The University of Maine

DigitalCommons@UMaine

Marine Sciences Faculty Scholarship

School of Marine Sciences

$3-10-2013$

\title{
Remote identification of the invasive tunicate Didemnum vexillum using reflectance spectroscopy
}

\author{
Thomas Leeuw \\ University of Maine \\ Seth O. Newburg \\ Massachusetts Institute of Technology \\ Emmanuel S. Boss \\ University of Maine, emmanuel.boss@maine.edu \\ Wayne H. Slade \\ Sequoia Scientific, Inc. \\ Michael G. Soroka \\ Massachusetts Institute of Technology
}

See next page for additional authors

Follow this and additional works at: https://digitalcommons.library.umaine.edu/sms_facpub

Part of the Oceanography and Atmospheric Sciences and Meteorology Commons

\section{Repository Citation}

Leeuw, Thomas; Newburg, Seth O.; Boss, Emmanuel S.; Slade, Wayne H.; Soroka, Michael G.; Pederson, Judith; Chryssostomidis, Chryssostomos; and Hover, Franz S., "Remote identification of the invasive tunicate Didemnum vexillum using reflectance spectroscopy" (2013). Marine Sciences Faculty Scholarship. 161.

https://digitalcommons.library.umaine.edu/sms_facpub/161

This Article is brought to you for free and open access by DigitalCommons@UMaine. It has been accepted for inclusion in Marine Sciences Faculty Scholarship by an authorized administrator of DigitalCommons@UMaine. For more information, please contact um.library.technical.services@maine.edu. 


\section{Authors}

Thomas Leeuw, Seth O. Newburg, Emmanuel S. Boss, Wayne H. Slade, Michael G. Soroka, Judith Pederson, Chryssostomos Chryssostomidis, and Franz S. Hover 


\title{
Remote identification of the invasive tunicate Didemnum vexillum using reflectance spectroscopy
}

\author{
Thomas Leeuw, ${ }^{1, *}$ Seth O. Newburg, ${ }^{2}$ Emmanuel S. Boss, ${ }^{1}$ \\ Wayne H. Slade, ${ }^{3}$ Michael G. Soroka, ${ }^{2}$ Judith Pederson, ${ }^{2}$ \\ Chryssostomos Chryssostomidis, ${ }^{2,4}$ and Franz S. Hover ${ }^{4}$ \\ ${ }^{1}$ School of Marine Sciences, University of Maine, Orono, Maine 04469, USA \\ ${ }^{2}$ MIT Sea Grant College Program, Massachusetts Institute of Technology, Cambridge, Massachusetts 02139, USA \\ ${ }^{3}$ Sequoia Scientific Inc., Bellevue, Washington 98005, USA \\ ${ }^{4}$ Department of Mechanical Engineering, Massachusetts Institute of Technology, Cambridge, Massachusetts 02139, USA \\ ${ }^{*}$ Corresponding author: thomas.leeuw@umit.maine.edu \\ Received 29 November 2012; accepted 10 February 2013; \\ posted 15 February 2013 (Doc. ID 180921); published 8 March 2013
}

\begin{abstract}
Benthic coverage of the invasive tunicate Didemnum vexillum on Georges Bank is largely unknown. Monitoring of $D$. vexillum coverage is vital to understanding the impact this invasive species will have on the productive fishing grounds of Georges Bank. Here we investigate using reflectance spectroscopy as a method for remote identification of $D$. vexillum. Using two different systems, a NightSea Dive-Spec and a combination of LED light sources with a hyperspectral radiometer, we collected in-situ measurements of reflectance from $D$. vexillum colonies. In comparison to reflectance spectra of other common benthic substrates, $D$. vexillum appears to have a unique spectral signature between 500 and $600 \mathrm{~nm}$. Measuring the slope of the spectrum between these wavelengths appears to be the most robust method for spectral identification. Using derivative analysis or principal component analysis, the reflectance spectra of D. vexillum can be identified among numerous other spectra of common benthic substrates. An optical system consisting of a radiometer, light source, and camera was deployed on a remotely operated vehicle to test the feasibility of using reflectance to assess $D$. vexillum coverage. Preliminary results, analyzed here, prove the method to be successful for the areas we surveyed and open the way for its use on large-scale surveys. (C) 2013 Optical Society of America
\end{abstract}

OCIS codes: $\quad 010.4450,240.6645$.

\section{Introduction}

Reports of an invasive tunicate, Didemnum sp., in coastal areas of New England date back to the late 1980s [1]. In the past there has been controversy over the exact identification and origin of the species $[2, \underline{3}]$. However, a recent study has identified the invasive tunicate as Didemnum vexillum [4], first described

1559-128X/13/081758-06\$15.00/0

(C) 2013 Optical Society of America by Kott [5] in New Zealand. The means of introduction is not well known, however, it is likely that $D$. vexillum was introduced by the aquaculture of shellfish imported from Japan [6].

Since its introduction to New England waters, $D$. vexillum has expanded throughout the Gulf of Maine. It has been observed colonizing both inshore and offshore habitats, including the prized fishing grounds of Georges Bank. Didemnum vexillum was first observed on Georges Bank in 2002 and has since colonized large areas of the benthos [7]. Using 
photographic surveys of Georges Bank (2004-2005) it was estimated to cover $50 \%-90 \%$ of hard substrates over a $230 \mathrm{~km}^{2}$ survey area [1].

Didemnum vexillum is an invasive ecosystem engineer and may pose a threat to the Georges Bank ecosystem. Didemnum vexillum is able to form dense mats over hard substrates, even cobble bottoms. These mats are predicted to have numerous negative impacts including: smothering benthic organisms, reducing settlement of larvae, reducing shelter for juvenile fish, and preventing groundfish from feeding on benthic organisms [7]. Since the introduction of $D$. vexillum, the benthic species composition on Georges Bank has been noticeably altered [4].

In order to understand the impacts $D$. vexillum will have on Georges Bank, it is important to monitor its distribution. Photographic surveys are currently the method of choice for mapping $D$. vexillum coverage. However, current surveys could be improved by employing a simpler and more rapid method of identification. A possible solution is to identify D. vexillum using reflectance spectroscopy. Different substrates typically reflect light in a unique way based on their composition and roughness [8,9]. Using multispectral and/or hyperspectral radiometers, differences in the reflectance spectrum can be used to identify different substrates.

This technique has been used successfully to remotely identify substrates in numerous fields of study. Substrates on earth as well as other planets have been reliably identified based on their reflectance spectrum $[10,11]$. In the marine environment, reflectance has been used to identify benthic substrate composition in shallow waters [12-14].

In addition to physical studies, reflectance has also been used for biological applications. It has been successfully used to assess the health of crops from a remote location $[15,16]$. Off the coast of Washington, eelgrass beds have been identified from an autonomous underwater vehicle (AUV) using benthic reflectance [17]. We hypothesized that similar methods could be used to identify $D$. vexillum on Georges Bank. Benthic reflectance spectra from Georges Bank could be collected using a radiometer mounted on an AUV. If the reflectance spectrum of $D$. vexillum were unique, it would provide a rapid and accurate method of identification.

Large-scale surveys using reflectance require automated substrate identification. This can be accomplished using numerous techniques [18]. In many applications, identification can be accomplished by simply calculating reflectance ratios using carefully chosen wavelengths $[16,17]$. In other cases, derivative analysis can amplify even subtle features in the reflectance spectrum [19].

To investigate the reflectance from $D$. vexillum mats, we compared benthic reflectance spectra of $D$. vexillum with numerous other substrates. From this, we were able to identify unique features in the $D$. vexillum reflectance spectrum, and used these features to develop an algorithm for automated detection. Last, we deployed an optical system on a remotely operated vehicle (ROV) to test the feasibility of identifying $D$. vexillum from a remote platform.

\section{Methods}

Two days of fieldwork were conducted in June 2010 to collect in-situ reflectance data. Divers at the Darling Marine Center in Walpole, ME, collected reflectance spectra from various substrates including $D$. vexillum. Spectra were collected using both a NightSea DiveSpec [20] and a Satlantic Hyperspectral Ocean Color Radiometer (HyperOCR). Additional spectra were collected in a flowing seawater lab using the DiveSpec. When using the DiveSpec, reflectance measurements were collected approximately $5 \mathrm{~cm}$ from the substrate under illumination from the built in LEDs. Substrates measured with the HyperOCR were illuminated using an LED Aquasun dive light. The dive light helped to enrich incident light in blue and red wavelengths (which are attenuated by the water column). LED illumination was chosen for efficiency and spectral stability over time. Reflectance measurements using the HyperOCR were made roughly $1 \mathrm{~m}$ from the substrate.

During in-situ data collection, the HyperOCR was connected by a power and communications cable above the sampling location, where data were logged continuously on a laptop computer. The radiometer lens cap was used as a delimiter between samples. Using notes taken by the divers and the delimiter between samples, the dataset was organized according to substrate. Substrates measured with the DiveSpec were identified by headings entered by the diver.

We applied corrections to our radiance measurements to account for both changes in the ambient light field and for attenuation of light by suspended particles between the radiometer and the substrate. This was achieved by referencing our measurements to the radiance spectrum from a surface of known reflectance. Reflectance from a Spectralon plaque, calibrated to diffusely reflect $95 \%$ of incident light, was frequently measured with the HyperOCR. The DiveSpec was corrected using a Spectralon plaque calibrated to reflect $99 \%$ of incident light. The reflectance spectrum from every substrate measured was normalized by the area under the spectrum, and then divided by the reflectance spectrum of the closest Spectralon plaque measurement. Area normalization was essential to account for any changes in the illumination intensity between standard and substrate measurements. The corrections applied to the spectra are described by Eq. $\underline{1}$ :

$$
\tilde{R}(\lambda)=\left(\frac{L(\lambda)}{\int_{425 \mathrm{~nm}}^{700 \mathrm{~nm}} L(\lambda) \mathrm{d} \lambda}\right) /\left(\frac{L^{*}(\lambda)}{\int_{425 \mathrm{~nm}}^{700 \mathrm{~nm}} L^{*}(\lambda) \mathrm{d} \lambda}\right),
$$

where $L(\lambda)$ is the radiance measured from the substrate, $L^{*}(\lambda)$ is the radiance measured from the Spectralon plaque, and $\tilde{R}(\lambda)$ is the area normalized reflectance. The HyperOCR measures radiance from 
350 to $800 \mathrm{~nm}$, however the spectra were truncated to $425-700 \mathrm{~nm}$ because of noise in the ultraviolet and near infrared. The light sources used in this study did not provide adequate light at these wavelengths, which lead to low signal to noise ratios in these regions.

In December 2011 the ROV Reef Explorer II was deployed at the Sunset Bay Marina in Hull, MA. It was outfitted with a forward facing HyperOCR and LED light source. The ROV was also equipped with a forward facing camera. A Spectralon plaque was lowered into the water to allow for in-situ measurement of its reflectance. Following measurement of the Spectralon plaque, the ROV collected reflectance spectra from $D$. vexillum encrusted dock pilings and from benthic mud and algae. Spectra were normalized and referenced to the Spectralon plaque using the same method described earlier [Eq. (1)]. Area normalized reflectance spectra were matched to images from the camera by timestamp. This allowed for identification of the substrate that the spectrum was collected from.

The fraction of the camera's field of view occupied by the dock piling (that was of known diameter) was used to calculate distance between the radiometer and the piling. Using the distance and the radiometer acceptance angle, a circle representing the radiometer field of view was overlaid on each image (Fig. 1). Spectra of the Spectralon plaque were easily distinguishable from all other spectra. The images that corresponded to these spectra were used to estimate the most likely offset angle of the radiometer in relation to the optical axis of the camera. The offset angle was used to adjust the position the circle representing the radiometer field of view.

\section{Results}

\section{A. Darling Marine Center}

Reflectance spectra from ten different colonies of $D$. vexillum were recorded in the lab and in-situ

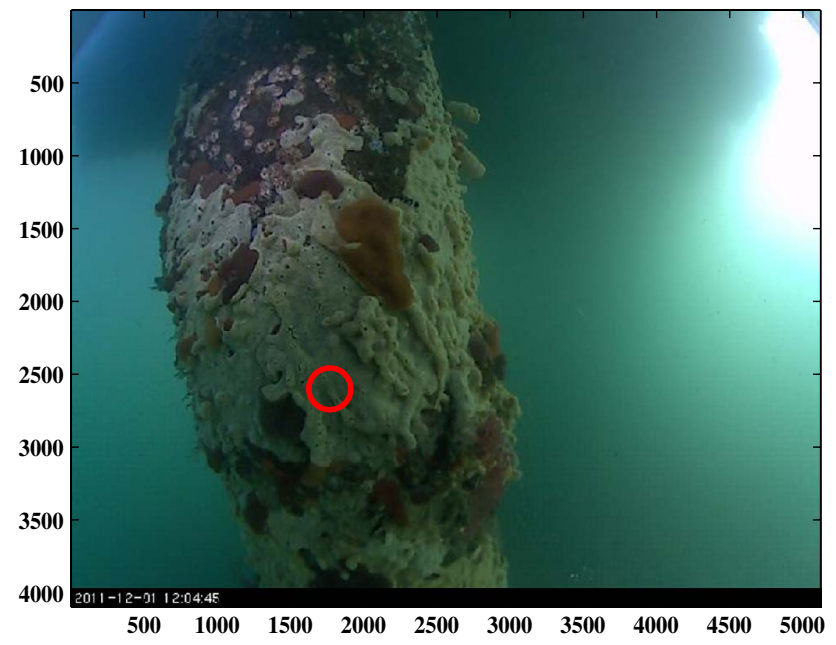

Fig. 1. (Color online) Image of $D$. vexillum taken by the ROV. The red circle marks the field of view of the radiometer. Axis labels denote pixel number. using the DiveSpec (http://misclab.umeoce.maine .edu/research/SpecIndex/spec_index.htm). The reflectance spectra all showed a characteristic shape with high reflectance near $600 \mathrm{~nm}$. The variation in the reflectance spectrum between colonies was small. The variation was smallest near $525 \mathrm{~nm}$ (Fig. 2A).

Reflectance spectra from seven different $D$. vexillum colonies were collected in-situ using the HyperOCR. All reflectance spectra were similar in shape and showed little overall variation. However, there was larger uncertainty in the short and long wavelengths (Fig. 2B). In comparison to spectra collected with the DiveSpec, the orange peak at $600 \mathrm{~nm}$ was less defined.

Compared to reflectance spectra of the most common substrates we encountered, the reflectance spectrum of $D$. vexillum is most unique between 500 and $600 \mathrm{~nm}$. Reflectance spectra of many inorganic substrates (e.g., mud, sand, shells) appear relatively featureless in comparison to $D$. vexillum [12] (Fig. 3A). In comparison to biological substrates, the reflectance spectrum of $D$. vexillum still maintains unique features. Even in comparison to another unidentified species of tunicate, the slope of the spectra between 500 and $600 \mathrm{~nm}$ is considerably different (Fig. 3B).

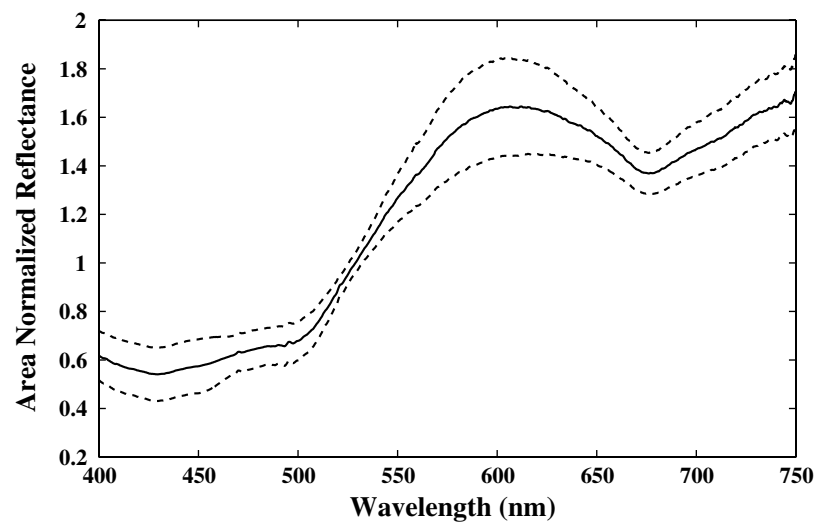

A

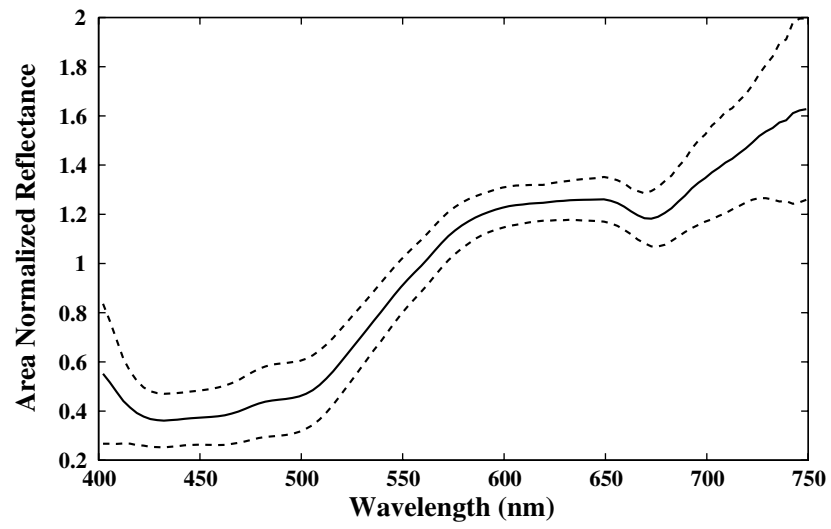

B

Fig. 2. (A) Mean in-situ reflectance spectra for $D$. vexillum using the DiveSpec $(n=10)$ and (B) the HyperOCR $(n=7)$. All spectra are referenced to a $95 \%$ reflectance standard. Dashed lines show $95 \%$ confidence interval. 


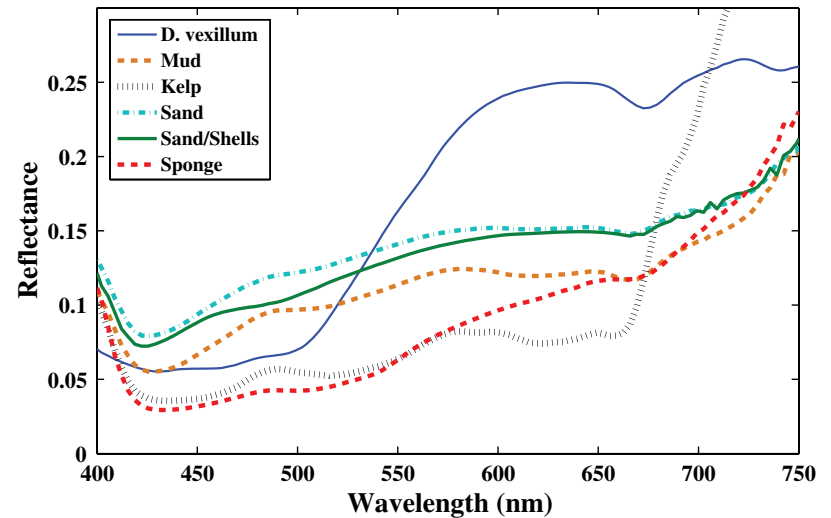

A

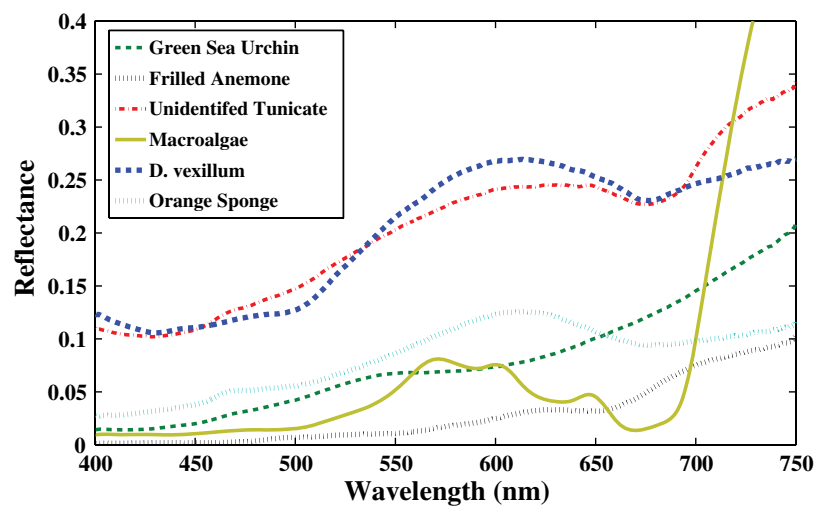

B

Fig. 3. (Color online) Comparison of $D$. vexillum spectra with other common substrates measured using (A) the HyperOCR and (B) the DiveSpec. Spectra are not area normalized and have been left as fractional reflectance $\left(L(\lambda) / L^{*}(\lambda)\right)$ to allow for easier visual comparison.

The first derivatives of the reflectance spectra collected at the Darling Marine Center were used to generate a detection algorithm. Area normalized spectra [Eq. (1)] were smoothed using a $15 \mathrm{~nm}$ moving average filter. The first derivative of the

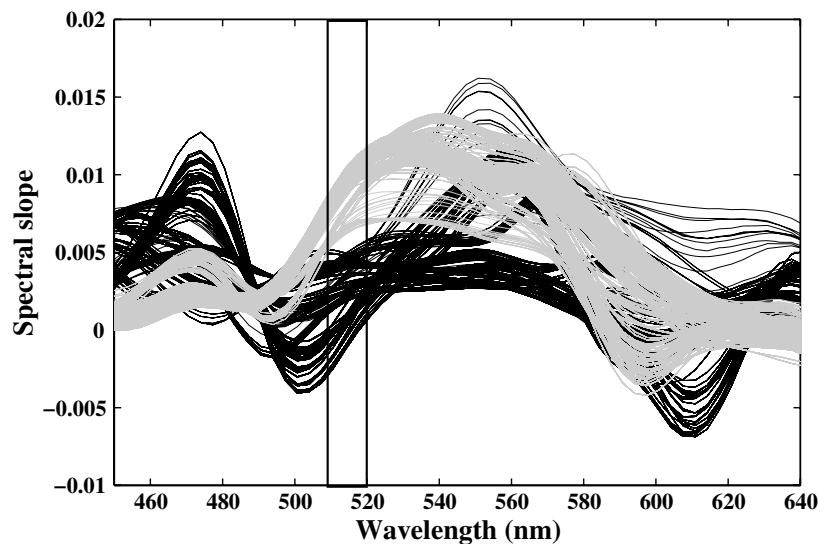

Fig. 4. First derivative spectra of $D$. vexillum (gray) and all other substrates measured (black). The box encloses the unique wavelengths $(510-520 \mathrm{~nm})$ that were used in the detection algorithm. Inside the box there is large separation between $D$. vexillum spectra and all other spectra collected. smoothed spectrum was calculated using a $3 \mathrm{~nm}$ interval (resolution of the HyperOCR) then interpolated to every nanometer between 425 and $700 \mathrm{~nm}$. The first derivative of the $D$. vexillum spectrum was consistently higher between 510 and $520 \mathrm{~nm}$ in comparison to all other spectra collected (Fig. 4). The average first derivative value from 510 to $520 \mathrm{~nm}$ was used to assign each spectrum a score value:

$$
S=\left(\frac{\sum_{510 \mathrm{~nm}}^{52 \mathrm{~nm}} \tilde{R}^{\prime}(\lambda)}{11}\right) * 1000,
$$

where $\tilde{R}^{\prime}(\lambda)$ is the first derivative of the area normalized reflectance spectrum with respect to wavelength and $S$ is the score value. The mean score value for $D$. vexillum spectra measured by the HyperOCR was $9.41 \pm 1.35(\alpha=0.05, N=7)$. No other substrate achieved a score value within this confidence interval. The highest score value recorded from a substrate other than $D$. vexillum was 4.82 . This score value was from a species of sponge.

\section{B. Sunset Bay Marina}

Approximately 700 spectra were collected during the hour deployment of the ROV. The ROV collected images and spectra from dock pilings covered in $D$. vexillum and various species of macroalgae. Spectra of open water and benthic mud were also collected. Score values were calculated for all spectra collected [Eq. (2)] and were used to test the effectiveness of the identification algorithm. All spectra with a score value within 1.5 standard deviations of the mean score value were classified as $D$. vexillum $(9.41 \pm 2.99)$.

Using this method, 155 spectra out of the 700 spectra collected were classified as $D$. vexillum. Based on images taken by the ROV, only two out of the 155 spectra were false positives. These two spectra were taken while the ROV was scanning across a section of the dock piling containing macroalgae. There were ten $D$. vexillum spectra that were missed by the detection algorithm (false negative). These spectra were either collected at a range greater then $1.3 \mathrm{~m}$ or the $D$. vexillum colony being measured was in direct sunlight. Overall, the algorithm was able to discriminate between $D$. vexillum and other substrates $98 \%$ of the time.

\section{Discussion}

The reflectance spectrum of $D$. vexillum was found to have characteristics sufficient to uniquely differentiate it among the spectra of other organisms and substrates we collected. For the areas surveyed in this study, the detection algorithm was able to accurately identify $D$. vexillum based on its reflectance signature. This has shown that $D$. vexillum can be detected using little computational effort. This approach can have many advantages, including faster processing of data and real time detection of $D$. vexillum. Real time detection onboard the AUV also opens up the possibility for adaptive feature mapping [21]. 
Our dataset includes only a small portion of the substrates likely to be encountered on Georges Bank. Collection and comparison of more reflectance spectra in the future will determine if our algorithm must be revised. If we find the detection accuracy unsatisfactory, higher order statistical methods could be employed. Principal component analysis (PCA) has been used for spectral identification of numerous substances and substrates [22-24]. This type of analysis can also be used to generate a more robust method for spectral identification of $D$. vexillum. All the substrates measured with the HyperOCR during fieldwork at the Darling Marine Center can be identified using a PCA conducted on the first derivative of the spectra between 490 and $557 \mathrm{~nm}$ (Fig. 5). In addition to presence or absence of $D$. vexillum, this could provide additional information about benthic habitat on Georges Bank.

The results of this study open the way for larger scale optical surveys of $D$. vexillum on Georges Bank. A downward facing radiometer and light source mounted on an AUV, such as the Odyssey IV [25,26], could be used to collect benthic reflectance spectra on Georges Bank. Using the methods described in this study, the data collected would provide a rapid and accurate assessment of $D$. vexillum coverage. However, the success of this method relies on a few key assumptions that must be addressed.

In shallow waters, $D$. vexillum has been observed to show seasonal variation in colony size and color [27]. This has been attributed to a decline in heath associated with lower water temperatures. However, we did not find significant changes in the reflectance spectrum. In our study, the $D$. vexillum reflectance spectra collected in December corresponded well with the reflectance spectra collected in June. However, seasonal variation in $D$. vexillum health and color has not been observed on Georges Bank [27], possibly due to more stable water temperatures.

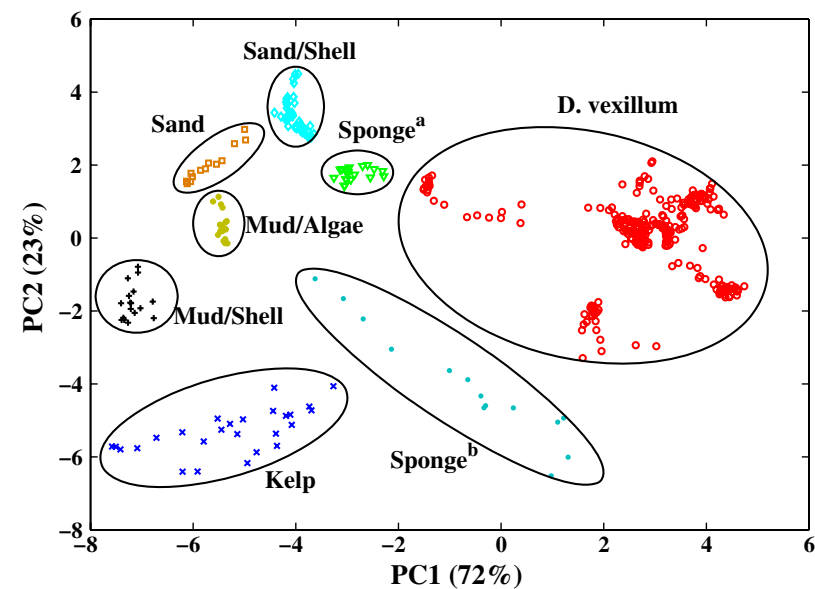

Fig. 5. (Color online) Score plot from a PCA of first derivative spectra from 490 to $557 \mathrm{~nm}$. The first two principal components are plotted, accounting for 95\% of the variation within the data. All substrates are easily distinguishable. The two distant D. vexillum groups were spectra collected under low illumination.
Settlement of other organisms on the surface of $D$. vexillum mats poses a potential problem for the detection method. Absorption of light by pigments of fouling organisms would alter the reflectance spectrum, masking the signal from $D$. vexillum. However, $D$. vexillum mats observed on Georges Bank appear to have clean surfaces, free of other organisms [27]. This may be due to compounds produced by $D$. vexillum. Many tunicate species, including members of the Didemnum genus, have been found to produce anti-predatory chemical deterrents [28]. Such chemical deterrents would reduce fouling and ensure an uncontaminated reflectance signal from the surface of the mat.

Another potential issue is changes in the optical properties of the water between the radiometer and the substrate. Our method assumes that they are constant from the time the Spectralon plaque is measured to the time a spectrum is collected. During the ROV deployment, the Spectralon plaque was measured at the beginning of the deployment and used to correct all spectra that were later collected. Thus, changes in the optical properties of the water and sample illumination (i.e., shaded versus full sunlight) over the course of the experiment likely contributed to false negatives.

The detection algorithm uses wavelengths from 510 to $520 \mathrm{~nm}$, where the variability in absorption is mostly due to phytoplankton [29]. During surveys, the phytoplankton community structure is likely to change in space and time. This will cause a change in the optical properties of the water that, if not accounted for, will make it harder to distinguish between substrates. Changes in the ambient light field would lead to similar errors. This is important because the light field in the ocean is variable and depends on a number of oceanographic and atmospheric conditions [30]. Thus, when using an AUV platform, the time and space between Spectralon plaque measurements and collection of spectra should be minimized.

There are numerous methods that could be used to correct for changes in substrate illumination. Two radiometers could be mounted on the AUV, one pointed at the seafloor and other pointed at a Spectralon plaque (similar to what was used in Moline et al. [17]). Both the seafloor and the Spectralon plaque would be illuminated using the same type of LEDs. A second, and calibration independent, solution would be to use a mechanical system to move a single radiometer. The radiometer could be alternated between two positions, one pointing at the seafloor and one pointing at a Spectralon plaque mounted on the AUV. This could be further simplified by pointing the radiometer at a rotating mirror. Changing the angle of mirror would determine whether the radiometer receives a signal from the seafloor or the Spectralon plaque. This method could also be used to scan the seafloor for increased spatial coverage.

The results of this study show that the reflectance spectrum of $D$. vexillum can be successfully identified 
from a remote platform. Using the methods in this study, the distribution of $D$. vexillum on Georges Bank could be mapped rapidly and accurately. Ability to detect and map $D$. vexillum will help determine the ecological ramifications of the $D$. vexillum colonization. The reflectance data collected by the surveys could also be used for a number of additional studies including mapping of benthic habitat on Georges Bank.

We thank S. Arnold and M. Sauer for help in diving at the Darling Marine Center. This work has been funded by NOAA Sea Grant NA10OAR4170081 to E. Boss, NOAA Sea Grant NA10OAR4170086 to F. Hover, and Office of Naval Research N00014-1010759 to C. Chryssostomidis.

\section{References}

1. S. G. Bullard, G. Lambert, M. R. Carman, J. Byrnes, R. B. Whitlatch, G. Ruiz, R. J. Miller, L. Harris, P. C. Valentine, J. S. Collie, J. Pederson, D. C. McNaught, A. N. Cohen, R. G. Asch, J. Dijkstra, and K. Heinonen, "The colonial ascidian Didemnum sp. A: current distribution, basic biology, and potential threat to marine communities of the northeast and west coasts of North America," J. Exp. Mar. Biol. Ecol. 342, 99-108 (2007).

2. P. Kott, "A new species of Didemnum (Ascidiacea, Tunicata) from the Atlantic coast of North America," Zootaxa 732, 1-10 (2004).

3. A. Price, J. S. Collie, and D. Smith, "18s ribosomal RNA and cytochrome oxidase gene sequences of Didemnum sp., an invasive colonial tunicate," GSO Technical Report No. 2006-01, Summer Undergraduate Research Fellowship Program in Oceanography (University of Rhode Island, Graduate School of Oceanography, 2005), Narragansett, RI, pp. 46-53.

4. N. L. Lengyel, J. S. Collie, and P. C. Valentine, "The invasive colonial ascidian Didemnum vexillum on Georges Bank ecological effects and genetic identification," Aquat. Invas. 4, 143-152 (2009).

5. P. Kott, "A complex didemnid ascidian from Whangamata, New Zealand," J. Mar. Biol. Assoc. UK 82, 625-628 (2002).

6. J. Dijkstra, L. G. Harris, and E. Westerman, "Distribution and long-term temporal patterns of four invasive colonial ascidians in the Gulf of Maine," J. Exp. Mar. Biol. Ecol. 342, 61-68 (2007).

7. P. C. Valentine, J. S. Collie, R. N. Reid, R. G. Asch, V. G. Guida, and D. S. Blackwood, "The occurrence of the colonial ascidian Didemnum sp. on Georges Bank gravel habitat: ecological observations and potential effects on groundfish and scallop fisheries," J. Exp. Mar. Biol. Ecol. 342, 179-181 (2007).

8. J. C. Price, "How unique are spectral signatures?" Remote Sens. Environ. 49, 181-186 (1994).

9. J. R. V. Zaneveld and E. Boss, "The influence of bottom morphology on reflectance: theory and two-dimensional geometry model," Limnol. Oceanog. 48, 374-379 (2003).

10. R. N. Clark, G. A. Swayze, K. E. Livo, R. F. Kokaly, S. J. Sutley, J. B. Dalton, R. R. McDougal, and C. A. Gent, "Imaging spectroscopy: earth and planetary remote sensing with the USGS Tetracorder and expert systems," J. Geophys. Res. 108, 5131 (2003).

11. B. L. Ehlmann, J. F. Mustard, S. L. Murchie, F. Poulet, J. L. Bishop, A. J. Brown, W. M. Calvin, R. N. Clark, D. J. Des Marais, R. E. Milliken, L. H. Roach, T. L. Roush, G. A. Swayze, and J. J. Wray, "Orbital identification of carbonatebearing rocks on Mars," Science 322, 1828-1832 (2008).

12. P. J. Werdell and C. S. Roesler, "Remote assessment of benthic substrate composition in shallow waters using multispectral reflectance," Limnol. Oceanog. 48, 557-567 (2003).
13. E. M. Louchard, R. P. Reid, and F. C. Stephens, "Optical remote sensing of benthic habitats and bathymetry in coastal environments at Lee Stocking Island, Bahamas: a comparative spectral classification approach," Limnol. Oceanog. 48, 511-521 (2003).

14. H. M. Dierssen, R. C. Zimmerman, R. A. Leathers, T. V. Downes, and C. O. Davis, "Ocean color remote sensing of seagrass and bathymetry in the Bahamas Banks by high-resolution airborne imagery," Limnol. Oceanog. 48, 444-455 (2003).

15. P. K. Goel, S. O. Prasher, J. A. Landry, R. M. Patel, R. B. Bonnell, A. A. Viau, and J. R. Miller, "Potential of airborne hyperspectral remote sensing to detect nitrogen deficiency and weed infestation in corn," Comput. Electron. Agric. 38, 99-124 (2003).

16. K. L. Smith, M. D. Steven, and J. J. Colls, "Use of hyperspectral derivative ratios in the red-edge region to identify plant stress response to gas leaks," Remote Sens. Environ. 92, 207-217 (2004).

17. M. A. Moline, D. L. Woodruff, and N. R. Evans, "Optical delineation of benthic habitat using an autonomous underwater vehicle," J. Field Robot. 24, 461-471 (2007).

18. D. Manolakis and G. Shaw, "Detection algorithms for hyperspectral imaging applications," IEEE Signal Process. Mag. 19, 29-43 (2002).

19. F. Tsai and W. Philpot, "Derivative analysis of hyperspectral data," Remote Sens. Environ. 66, 41-51 (1998).

20. C. H. Mazel, "In-situ measurement of reflectance and fluorescence spectra to support hyperspectral remote sensing and marine biology research," Oceans 2006 Conference, $1-4$.

21. A. A. Bennet and J. J. Leonard, "A behavior-based approach to adaptive feature detection and following with autonomous underwater vehicles," IEEE J. Oceanic Eng. 25, 213-226 (2000).

22. A. A. Da Silva, D. De Keukeleire, D. R. Cardoso, and D. W. Franco, "Multivariate analysis of UV-Vis absorption spectral data from cachaca wood extracts: a model to classify aged Brazilian cachacas according to the wood species used," Anal. Methods 4, 642-646 (2012).

23. P. D. Hunter, A. N. Tyler, M. Presing, A. W. Kovacs, and T. Preston, "Spectral discrimination of phytoplankton color groups: the effect of suspended particulate matter and sensor spectral resolution," Remote Sens. Environ. 112, 1527-1544 (2008).

24. K. Y. Noonan, L. A. Tonge, O. S. Fenton, D. B. Damiano, and K. A. Frederick, "Rapid classification of simulated street drug mixtures using raman spectroscopy and principal component analysis," Appl. Spectrosc. 63, 742-747 (2009).

25. S. Desset, R. Damus, F. Hover, J. Morash, and V. Polidoro, "Closer to deep underwater science with Odyssey IV class hovering autonomous underwater vehicle (HAUV)," National Sea Grant Library, MIT-R-05-004 (2005).

26. J. Eskesen, D. Owens, M. Soroka, J. Morash, F. S. Hover, and C. Chryssostomidis, "Design and performance of Odyssey IV: a deep ocean hover-capable AUV," National Sea Grant Library, MIT- T-09-006 (2009).

27. P. C. Valentine, M. R. Carman, D. S. Blackwood, and E. J. Heffron, "Ecological observations on the colonial ascidian Didemnum sp. in a New England tide pool habitat," J. Exp. Mar. Biol. Ecol. 342, 109-121 (2007).

28. D. P. Pisut and J. R. Pawlik, "Anti-predatory chemical defenses of ascidians: secondary metabolites or inorganic acids?" J. Exp. Mar. Biol. Ecol. 270, 203-214 (2002).

29. C. S. Roesler, M. J. Perry, and K. L. Carder, "Modeling in-situ phytoplankton absorption from total absorption spectra in productive inland marine waters," Limnol. Oceanog. 34, 1510-1523 (1989).

30. S. Sathyendranath and T. Platt, "The spectral irradiance field at the surface and in the interior of the ocean: a model for applications in oceanography and remote sensing," J. Geophys. Res. 93, 9270-9280 (1988). 